\title{
Ballistocardiogram K關する臨床的研究
}

\author{
第 3 報 三, 三降圧劑使用時の變化

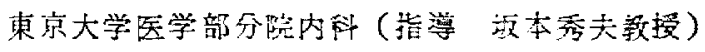 \\ 山田濡雄
}

\section{CLINICAL STUDIES ON THE BALLISTOCARDIOGRAM \\ (3 REPORT) BALLISTOCARDIOGRAPHIC RESPONSES IN HYPERTENSIVE PATIENTS TO ACUTE EXPERIMENTS OF DEPRESSOR DRUGS}

\author{
$\mathrm{BY}$ \\ Mitsuo Yamada \\ Medical Department of Branch Hospital, \\ the University of Tokyo, School of Medicine \\ (Prof.: Hideo Sakamoto)
}

This study concerns the longitudinal and lateral ballistocardiographic responses of 20 hypertensive patients to parenteral administration, in acute experiments, of 1-hydrazinophthalazine, pentolinium tartarate, benzylimidazoline and amobarbital sodium.

Each drug proved capable of producing a striking changes of abnormal ballistocardiographic pattern toward normal and of increasing IJ amplitude in certain patients. With respect to qualitative improvement in the ballistocardiogram the order was: 1-hydrazinophthalazine, pentolinium tartarate, benzylimidazoline and amobarbital sodium (listed in decreasing order). With respect to increasing of IJ amplitude the following was the order: 1-hydrazinophthalazine, pentolinium tartarate, amobarbital sodium and benzylimidazoline. But the ballistocardiographic changes did not always paralleled the hypotensive response of blood pressure. However, benzylimidazoline produced the marked ballistocardiographic response without lowering the blood pressure.

\section{緒言}

Ballistocardiography は心電図，心カテーテル 法などの检查法とは全く罢なつた性貸の検查方法 であつて，Starri”の発表以来多くの研究成續が 発表されていることは，すでに述べたが，その装 置が昰を伴ない易いことを指摘されて，今までに 本法に関して物理的，または，機械的の研究が行 われ，最近になつて，ようやく，歪の少ない，䠰
床的に滥足し 得る装霬を von Wittern'光, Scarborough $^{3)}$, Deuchar ${ }^{4)}$, 籼 5)，笹本6) らが報告 している、そして、これらの装置を用いて種々の 臨床成績が発表されている。わたくしはすすた に，米山の発表した装置を利用して正常健康人， 本態性尚血圧症喼楛より得られた成績を述べた が，本報においては，筒血压㭧渚に 1-Hydrazinophthalazine, Pentolinium tartarate, Benzyli- 
midazoline, および Amobarbital natrium を使 用して認められる Ballistocardiogram の変化に ついて検婆を行なつたので報告する。

\section{检查對象}

收樎期压が $180 \mathrm{mmHg}$ 以上, 拡張期圧が $120 \mathrm{~mm} \mathrm{Hg}$ 以上の高血圧患者20例を本実験の対象とした。性 別は男子13例，女子 7 例で, 年令は40〜 59才, 平 均52.3才である。電図検查では心肥大，冠不 全，あるいは，心筋硬塞の如き異常を示すもの， X線検查によつて心陰影，維隔洞に変化のあるも の，心蔵部聴診により心雑音を聴取し得るもの， 蛋白尿のあるもの，および，己往に心不全，また は，心喘息を起した症例は本研觉の対象より除外 した。

\section{检查方法}

装置は前に述べたように，米山の vector Ballistocardiograph を用いた。被㭘者は己報の通り， 少なくとも, 食後 3 時間以上を経過し, Ballisto- cardiograph 上で，少なくとも20分は安静を保 たせた後に，10分の間腷て 2 回記録を行い, 次 に，下記に远へる降圧剂を使用して Ballistocardiogram の変化を追求した。

検查に使用した薬剂。

\section{A) 1-Hydrazinophthalazine}

20～10mg，平均15.8mg 筋肉内に注射し，注射 後30分，60分に Ballistocardiogram を記録し, 同時に血压を測定した。なお，60分で血圧の下降 が著明の場合には，90分，120分後に検查を行な つた症例もある。

\section{B) Pentolinium tartarate}

25mg 節肉内に注射し, 1-Hydrazinophthalazine の場合と同様に検查を行なつた。

\section{C) Benzylimidazoline}

10〜20mg, 平均 $18.2 \mathrm{mg}$ を静脈内に30秒前後で注 入した. 注入後 2 分, 4 分, 6 分, 8 分, 10 分目 に30秒，ないし 1 分間 Ballistocardiogram を記

第 1 表 各種降王剤にょる血正降下度とその使用量

\begin{tabular}{|l|c|c|c|c|c|}
\hline & \multicolumn{2}{|c|}{ 血任降下度 } & \multicolumn{2}{|c|}{ 使 } & 用 \\
\cline { 2 - 5 } & 平均 & 範 & 囲 & 平 均 & 範 \\
\hline 1-Hydrazinophthalazine & $23 / 20$ & $10 / 15 \sim 50 / 35$ & $15.8 \mathrm{mg}$ & $20 \mathrm{mg} \sim 10 \mathrm{mg}$ \\
\hline Pentolinium tartarate & $28 / 22$ & $15 / 13 \sim 60 / 40$ & $25 \mathrm{mg}$ & $25 \mathrm{mg} \sim 12.5 \mathrm{mg}$ \\
\hline Benzylimidazoline & $10 / 5$ & $0 / 0 \sim 20 / 10$ & $18.2 \mathrm{mg}$ & $20 \mathrm{mg} \sim 10 \mathrm{mg}$ \\
\hline Amobarbital natrium & $15 / 8$ & $10 / 8 \sim 15 / 12$ & $333 \mathrm{mg}$ & $500 \mathrm{mg} \sim 250 \mathrm{mg}$ \\
\hline
\end{tabular}

第 2 表 各種降王剤の注射前後にみられら波形異常の変化

\begin{tabular}{|c|c|c|c|c|c|c|c|c|c|c|}
\hline & 症例数 & & $\begin{array}{c}\text { small } \\
\mathrm{H}\end{array}$ & $\begin{array}{c}\text { lavge } \\
\mathrm{H}\end{array}$ & $\begin{array}{l}\text { abnor- } \\
\text { mal I }\end{array}$ & wide & 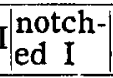 & $\begin{array}{l}\text { shal- } \\
\text { low I }\end{array}$ & $\begin{array}{l}\text { notch- } \\
\text { ed IJ }\end{array}$ & 計 \\
\hline \multirow{2}{*}{ 1-Hydrazinophthalazine } & \multirow{2}{*}{15} & 前 & 2 & 5 & 2 & 5 & $\overline{5}$ & 5 & 5 & 34 \\
\hline & & 後 & 2 & 5 & 0 & 0 & 2 & 3 & 3 & 18 \\
\hline \multirow{2}{*}{ Pentolinium tartarate } & \multirow{2}{*}{10} & 前 & & 4 & 2 & & 3 & 5 & 2 & 16 \\
\hline & & 後 & & 3 & 0 & & 2 & 4 & 1 & 15 \\
\hline \multirow{2}{*}{ Benzylimidazoline } & \multirow[t]{2}{*}{10} & 前 & 2 & 8 & 2 & & 8 & 5 & & 25 \\
\hline & & 後 & 0 & 6 & 1 & & 3 & 2 & & 12 \\
\hline \multirow{2}{*}{ Amobarbital natrium } & \multirow{2}{*}{5} & 前 & & 5 & & 5 & 5 & 5 & & 20 \\
\hline & & 後 & & 3 & & 4 & 5 & 5 & & 17 \\
\hline
\end{tabular}




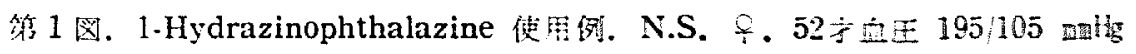
$4 a t$
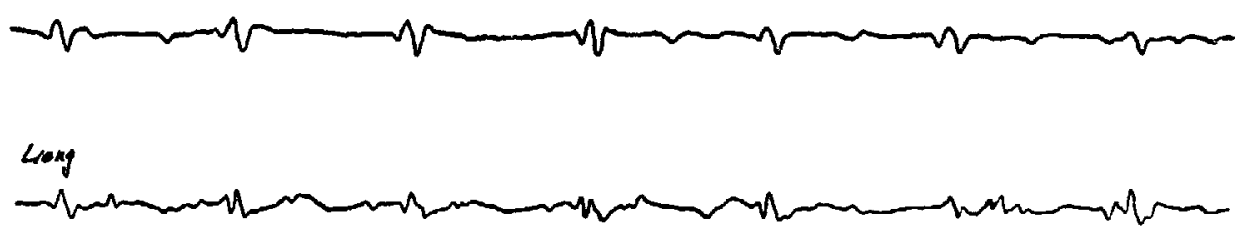

1-Hydrazinophthalazine $20 \mathrm{mg}$ 管肉内注射後30分 血E $150 / 80 \mathrm{~mm}$

Lat.
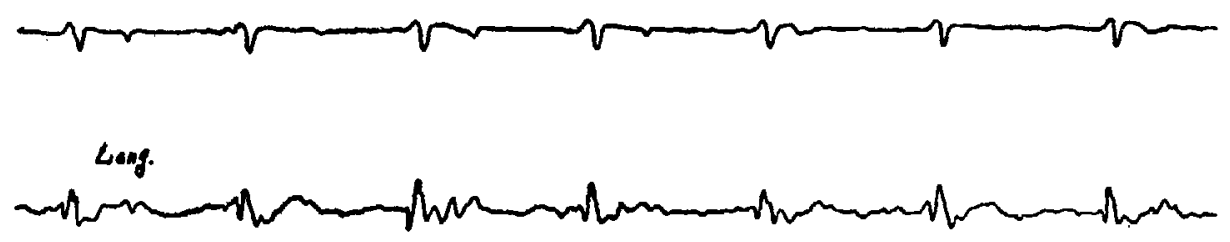

第 2 注. Pentolinium tartarate 使用例 N.O., 命, 58宁 $210 / 105 \mathrm{~mm} \mathrm{Hg}$

Lat.
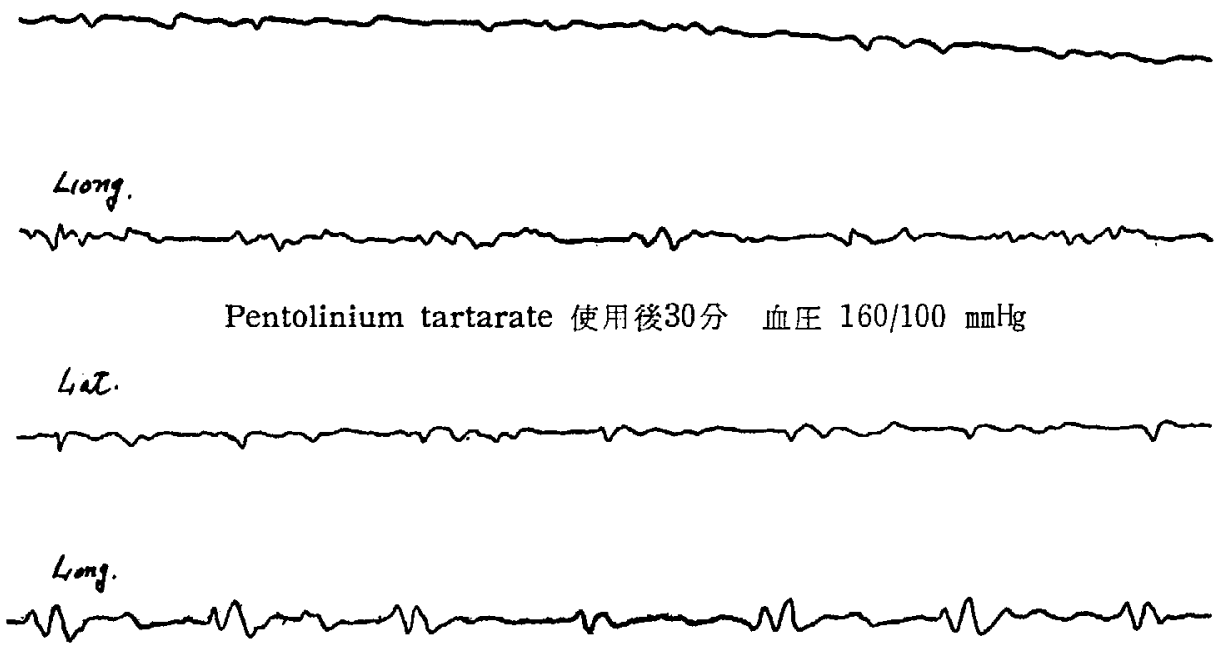

錄し，次に血圧を測定した。本剂を使用した場合 に誋められた血圧降下の程度は軽度で，かつそ の持続時間も短いので，10分以上追究した正例は なかつた。

D) Amobarbital natrium

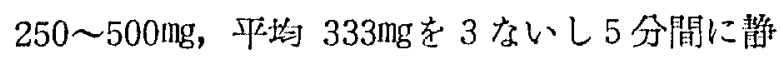
服内に注入し，注入後 5 分拀きに30分まで記録を 行なつた。

\section{検查成續}

\section{A）降圧削の使用量と血圧下降度}

上記の四種の薬剂の使用量と，その血圧下降 度は第 1 表に示すとおりであつて，1-Hydrazinophthalazine の血压降下作用が最も强く, Pentolinium tartarate, Benzylimidazoline, Amobarbital natrium の搭で小となている.

B）各種降圧绪の Ballistocardiogram の滛 形に及はす影響

1-Hydrazinophthalazine 注射持の Ballistocar- 


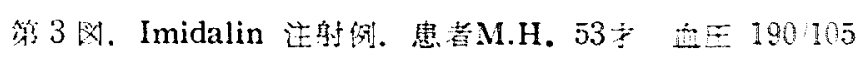

$4 \cdot t$

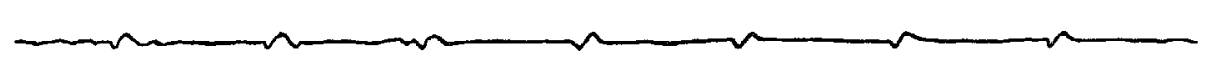

Long.

Imidalin 这射後 5 分 倍王 $185 / 100$

Lat.

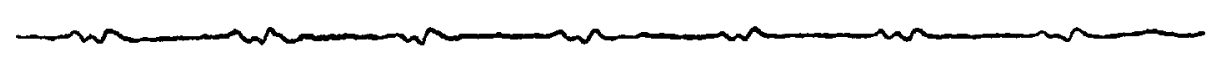

soog.

第 4 这. Amobarbital natrium 使用例. E.F. $P, 50 \div 210 / 120 \mathrm{mmHg}$

Lat.

Mrmm

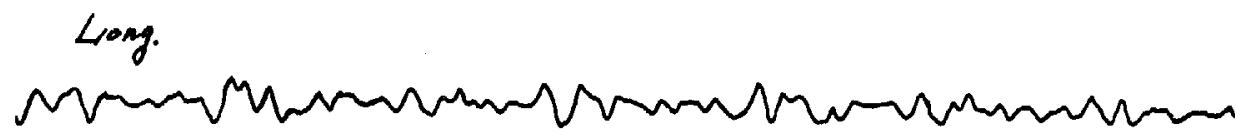

Amobarbital natrium $250 \mathrm{mg}$ 静脈内注射後20分. 血压 $180 / 115 \mathrm{mmlg}$

Lat.

Nom

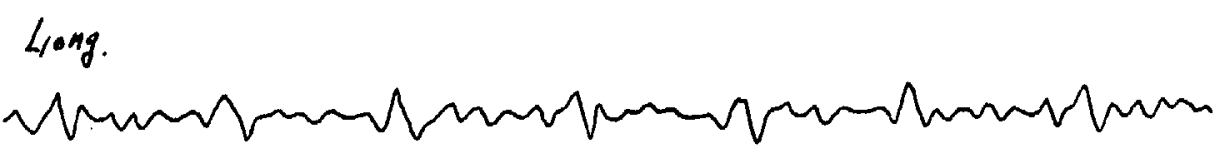

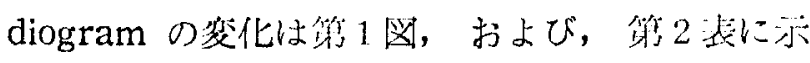
すと打りである。すなわち，注射前にみられた各

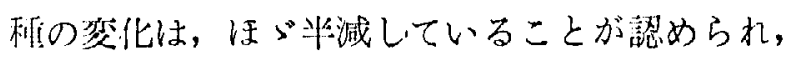

特にHI脚の界带，罗竖なI波，浅いI波などが

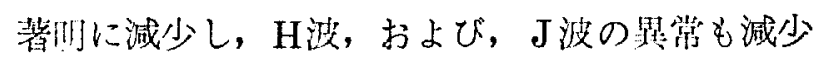
する偭间分諗められる。しかしこの上うな变化 


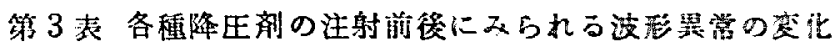

\begin{tabular}{|c|c|c|c|c|c|c|c|c|c|c|}
\hline & & & smal $\mathrm{H}$ & large $\mathrm{H}$ & $\begin{array}{l}\text { abnor- } \\
\text { mal HI }\end{array}$ & wide I & $\begin{array}{r}\text { notched } \\
\end{array}$ & notched & $\begin{array}{r}\text { shallow } \\
\text { I }\end{array}$ & 計 \\
\hline & 射 & & 4 & 18 & 6 & 10 & 21 & 7 & 20 & 86 \\
\hline & 射 & 後 & 2 & 11 & 1 & 4 & 12 & 4 & 14 & 48 \\
\hline & 少 & 染 & $50 \%$ & $61 \%$ & $17 \%$ & $40 \%$ & $57 \%$ & $57 \%$ & $70 \%$ & $56 \%$ \\
\hline
\end{tabular}

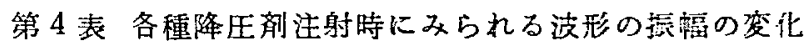

\begin{tabular}{|c|c|c|c|c|c|c|c|}
\hline & 症例数 & & H I 腒 & I J 的 & $\mathrm{HIE} / \mathrm{HII}$ & IJE/IJI & $\mathrm{HI} / \mathrm{IJ}$ \\
\hline \multirow{2}{*}{ 1-Hydrazinophthalazine } & \multirow{2}{*}{15} & 前 & \multirow{2}{*}{$+56 \%$} & \multirow{2}{*}{$+35 \%$} & $50.6 \%$ & $55.1 \%$ & $63.3 \%$ \\
\hline & & 後 & & & $62.3 \%$ & $58.8 \%$ & $69.7 \%$ \\
\hline \multirow{2}{*}{ Pentolinium tartarate } & \multirow{2}{*}{10} & 前 & \multirow{2}{*}{$+20 \%$} & \multirow{2}{*}{$+22 \%$} & $66.7 \%$ & $60.0 \%$ & $89.9 \%$ \\
\hline & & 後 & & & $72.0 \%$ & $50.0 \%$ & $53.4 \%$ \\
\hline \multirow{2}{*}{ Benzylimidazoline } & \multirow{2}{*}{10} & 前 & \multirow{2}{*}{$+16 \%$} & \multirow{2}{*}{$+19 \%$} & $45.9 \%$ & $50.1 \%$ & $64.8 \%$ \\
\hline & & 後 & & & $66.1 \%$ & $52.8 \%$ & $69.7 \%$ \\
\hline \multirow{2}{*}{ Amobarbital natrium } & \multirow[b]{2}{*}{ 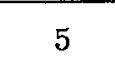 } & 前 & \multirow{2}{*}{$+32 \%$} & \multirow{2}{*}{$+30 \%$} & $55.6 \%$ & $53.5 \%$ & $52.0 \%$ \\
\hline & & 後 & & & $60.0 \%$ & $70.0 \%$ & $68.9 \%$ \\
\hline
\end{tabular}

第 5 表 各種降王剤注射時にみられる左右軸の Ballistocardiogram にみられる変化

\begin{tabular}{|l|r|r|r|r|}
\hline & 症例 & 著变 & 軽度 & 不変 \\
\hline 1-Hydrazinophthalazine & 15 & 2 & 5 & 8 \\
\hline Pentolinium tartarate & 10 & 1 & 4 & 5 \\
\hline Benzylimidazoline & 10 & 0 & 2 & 8 \\
\hline Amobarbital natrium & 5 & 0 & 2 & 3 \\
\hline
\end{tabular}

は血圧の下降とは必ずしも並行せず，降下ととも に異常な波形が出現した症例もあつた。第 2 表に おいて, 注射後の変化の数にはこの様な症例も含 められていることは注目すべきである。

Pentolinium tartarate 注射後の Ballistocardiogram の㚆化は第 2 図，およひ，第 2 表に示 すとおりである。すなわち，注射前にみられた各 種の变化は注射後に減少して，その樎小率は37.5 \%である．H I 脚の罢常は 1-Hydrazinophthalazine の場合と同じく消失しているが，異常なH 波, 浅いI波などの異常なI波は残つている。本 剂使用時にも 1-Hydrazinophthalazine 使用時と
同様に，注射前に異常が恋められないもので，使 用後に異常な波形が出現した症例があつた。

Benzylimidazoline 注射後の Ballistocardiogram の変化は第 3 図，㧈よび第 2 表に示すとお りである. 注射前にみられた Ballistocardiogram の異常は注射後減少している. 第 1 表上り 明らかなとおり，Benzylimidazoline 注射によつ て血圧の下降は比䩙的小さかつたが，波形の変 化がきわめて明らかなものと, ほとんど, 変化 のないものとに分れているように思われるのは， 1-Hydrazinophthalazine, Pentolinium tartarate, および Amobarbital natrium の使用時にみ られない変化であつた。

Amobarbital natrium 注射時の Ballistocardiogram の変化は第 4 図，および，第 2 表に示 すとおりである。すなわち，注射前の Ballistocardiogram の鼠常の減少は㬜明でないが，H波 の変化が，や>減少する傾向が認められた。

以上を小括すると次の如くになる。

a ）各種降圧剤の使用によつて Ballistocardiogram の買常の頻度は, 減少する傾问がある.この 
㖽间は 1-Hydrazinophthalazine, Benzylimidazoline, Pentolinium tartarate, Amobarbital natrium の順で弱いようである。

b ) Ballistocardiogram の各波の波型の变化 は第了表に示したように，HＩ脚の異常と，異常 に広いI 波の減少は蓉明で，大きいH波と浅い，I 波の, 注射後の頻度の減少の䝨向が小さいように 思われる。

c) 各種降圧剂の Ballistocardiogram の振幅 に及汪す影響

1-Hydrazinophthalazine 注射によつてH I振 幅, および I J振幅は增加の傾向が認められる。

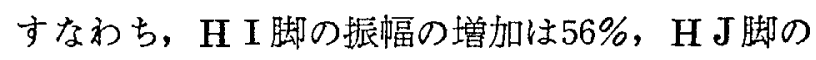
振幅の增加は 35\%である。しかし，IJE/IJI 比， HIE/HII 比および，HＩ／ＩＪ比には明らかな 変化汃認めら机ない(第 4 表)。

Pentolinium tartarate 使用時にも 1-Hydrazinophthalazine の場合々同様に，H I 脚，ＩJ脚 の振幅は境加しているが， HIE/HII 比と IJE/IJI 比は著明の変化が認められず，HＩ／ＩＪ比は著 明の減少が認められる。

Benzylimidazoline, および, Amobarbital natrium 注射時にも前二者と同様の変化が認められ るがすすでに述べたように，降圧の程度が小さい ので，変化もあまり明らかでなかつた。

以上に述べた所を小括すると, 各種降圧剤の使 用によりH I 脚, おょび I J脚の振幅は增大し, その增大の大きさは 1-Hydrazinophthalazine, Pentolinium tartarate, Amobarbital natrium, Benzylimidazoline の順に小となり，かつ，血圧 の下降度と振幅の変化の間に, 必ずしも, 证行関 係は諗められなかつた。 HIE/HIr比, IJE/IJI 比, および，HＩＩＪ比は注射によつて著明の変化 が認められなかつた。

D）各種降圧剂の左右軸の Ballistocardiogram に及涩す影響

降圧剤使用前後にみられる頭足方向の Ballistocardiogram の変化については上に述べたので， 以下に左右軸の Ballistocardiogram の変化につ
いて述べる. 左方蟽の Ballistocardiogram は頭 足軸の Ballistocardiogram に扎してその振偪が

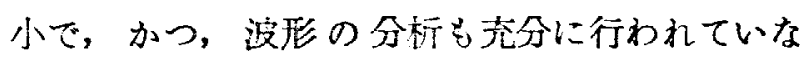
いのでわたくしは注射前後における左右軸の Ballistocardiogramを圠渂して, 著変, 軽度に变 化したものおよび，不変の 3 群に分けて検討し た．著変とは振湢, 波形両者に変化があるもの, 㪕度に变化したものとは振幅, 波形のいずれかに 强い変化があつたもの, 不変とは振幅,波形に変化 のなかつたものである. 1-Hydrazinophthalazine 注射持には $13 \% に$ 著変を，33\%に㪕度の变化が認 められた (第 5 表). Pentolinium tartarate 使 用時には $10 \% に$ 著変を，40\%に㪕度の变化が認め られた. Benzylimidazoline の注射後には軽度の 変化を示したものは20\%で, $80 \%$ で不変であつ た.Amobarbital natrium の場合には40\%で軽 度の変化がみられ，60\%は不亲であつた。すな わち，検查回数35回中，著变を示したものは 3 回 ( $9 \%)$, 軽度の変化を示したものは13回 $(37 \%)$ で，不変のものは24回（54\%）であつた。

な㧍，このような変化は頭足軸の場合と同じ く, 必ずしも，血圧の下降と並行関係は認められ なかつた。

\section{考案}

Ballistocardiogram に及济す各種薬剂の效果 については, Digitalis ${ }^{8)}$, Quinidine ${ }^{9)}$, Epinephri$\mathrm{ne}^{10)}$, Visamin $^{11)}$, Nitroglycerin, および, その 誘導体 ${ }^{12)}$, Nicotine ${ }^{13)}$, 白律神経遮断剂, Ether などに関して行われ, Apresolin, Hexamethonium, Veratrone, Regitine, および Sodium amytal については Roehm et al ${ }^{14)}$, Apresolin につ いては Riven et al $^{15)}$ が, Hexamethonium, および, Pentamethonium については Grobe et al16)がその結果を報告している。他方，本邦に おいては德政17が報告しているに過ぎない。

また，高血圧患者にみられる Ballistocardiogram の異常については多くの発表があるが，そ れらの異常波形の原因，または，成因については明 らかでない点が多く，血液を駆出する力が小とな 
つているためであると考えられているそててK 波以後の波については，すでに述べたように，装 置による阷を受忛易いので检討しないが，H波， I波，および，J波の鲢常波形についても血圧， 心拍出量，駆出速度，あるいは，末梢抵抗などが 関与していることは明らかである。しかし，昇压 物賀を正常血压，または，低血圧を示すものに注 射しても波形に変化を生ぜず，振幅にのみ変化が みられるとの報告もある。すなわち，血圧の変化 のみが Ballistocardiogram の波形を決定する大 きな因子でないことが認められる。

1-Hydrazinophthalazineを用いて Roehm et a14)は，著明な波形の改善を最大心力の增加を認 め, Riven et al ${ }^{15)}$ は Ballistocardiugram の波 形と振幅に有益な変化が認められたと報告してい る。わたくしは，すでに述べたように，波形，振 幅に著明の変化を譛めたことを述べたがここれは Roehm et $\mathrm{al}^{14)}$ ，および， Riven et $\mathrm{al}^{15)}$ の報告 と一致するものである.

Pentolinium tartarate を用いた結果を，Grob et $\mathrm{al}^{16)}$, Roehm et $\mathrm{al}^{14)}$, 徳政17)は述へている. Grob et al $^{16)}$ は methonium 化合物を静脈内 に注大し，14例中 5 例に改善，6例が不変であ つたと報告し， Roehm et al ${ }^{14)}$ は Hexamethonium を用いて Ballistocardiogram の波形，お よび，最大心力の変化に一定の傾向がみられない としている。わたくしは，本剂では，1-Hydrazinophthalazine 使用時に比較して Ballistocardiogram の罣常波形の減少率が小さく，かつ，使用 前より使用後に変化を示した症例が多かつたこと は上記の所見と一致し，興味のある点である。

Benzylimidazoline を用いて Roehm et al ${ }^{14)}$ は，血圧の降下が著明でない例で Ballistocardio-

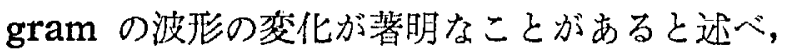
また, Benzylimidazoline の誘導体である Regitine 在用いて同粎の傾问がある上还べて，わたく しの得た絬果と，ほぶ，同一の，所見を発表してい る.

Amobarbital natrium を使用した例はないが,

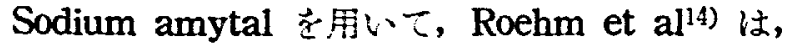
かなりの率で Ballistocardiogram に変化を生ぜ

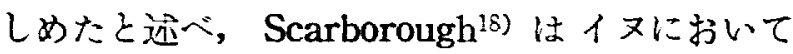
morphine-barbiturate を偾用した成績を発表し ているがわたくしの得た成續は，すでに述べた ように変化が少なかつたがこえれは使用量の相違 によるものと推定される。

以上，主として顽足軸の Ballistocardiogram について述べたが，左右軸の Ballistocardiogram についてこのような㚆化を追究したものは， Scarborough $^{18)}$ の動物実験以外に認められない。 March $^{19)}$ は左右軸の Ballistocardiogram の変 化を考慮して呼吸性变動を检討し, Honnig は健 康成人について述べているが，各程薬㓮の影響， あるいは，それ以外の問題について，今後十分の 検討を要する分野である。

降圧剤の使用後 Ballistocardiogram に異常波 形が出現することは，すでにわたくしも述べ， Roehm et a1 ${ }^{14)}$, Grob et $a^{16)}$ 述べているが, Roehm et al $^{14)}$ はこの原因について，大循環采 の血圧下降に伴ない，冠血流の減少，末梢血管抎 張による血流の貯留と，それによる静脈還流の減 少，心筋に対する面接作用，心予力の減少をあ げ，Scarborough ${ }^{18)}$ は薬物 の心筋に対する直接 作用を考え，Grob et $\mathrm{al}^{14)}$ は念激に生じた交感 神経遮断作用によるとして，さらに，検討を期街 される部分である。

\section{結論}

20例の本態性高血压患者に各種降圧剤を用いて 次の如き結果を得た。

（1）1-Hydrazinophthalazine 使用後には波 形哭常の娍少，振幅の增大が著明に認められた。

(2) Pentolinium tartarate 使用後には1-Hydrazinophthalazine ほぼ箸明の変化が, Ballistocardiogram に認められなかつた。

(3) Benzylimidazoline, および Amobarbital natrium 便用後には，罚常波形，および，振 幅の変化が少ないが，Benzylimidazoline 使用時 に向圧の降下が軽度でも，著明に変化する場合が 
あることを述べた。

(4) 左右軸の Ballistocardiogram でも降压 郕の使用により，変化が認められる。

（5）降圧㶡の使用による血压の下降度と，波 形,または, 振幅の亲化との間に一定の並行関係 はない。

\section{文献}

1) Starr, I.: Am. J. Physiol. $127: 1,1939$. 2) von Wittern, W.: Am. Heart J. $46: 705$, 1953. - 3) Scarborough, W.R. et al.: Bull. Johns Hopkins Hosp. $87: 235,1950.4$ ) Deuchar, D., et al.: Circulation, $11: 228,1957 .-5$ ) * 山要人：呼吸々循環，5:822,1957。一6）笹本浩

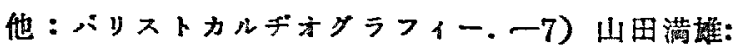
日内会誌, $47: 8,1958$. -8) Starr, I.: Am. J. Med. Sc. 202 : 469, 1941. -9) Gabner, R.: Jr. A. Libe. Im. Med. Dir. Am. $34: 20,1950 .-10$ ) Mandelbaum, H. et al.: Circulation, $5: 855$, 1952. - 11) Nalbeski, L. et al.: Circulation 5 : 851, 1952. -12) Brandt, J. et al.: Am. J. Med. $12: 650,1952$. - 13) Caccese, A., et al.: Am. Heart J. $42: 589,1951$. - 14) Roehm, D, et al.: Circulation, $7: 329,1953 .-15)$ Riven, S. et al.: Am. J. Med Sc. 14 : 160, 1953. -16) Grob, D. et al.: Circulation. $8: 352,1953 .-17)$ 徳政 義和：日内会誌, $45: 1297,1957$, -18) Scarborough, R.: Am. Heart J. $54: 651,1957$. -19) March, H.: Circulation. $12: 869,1955$. 